\title{
Craniums with clout
}

\section{A look at two early human fossils reveals the prejudices in ideas about human evolution, finds Henry Gee.}

W e have all seen the canonical parade of apes, each one becoming more human. We know that, as a depiction of evolution, this line-up is tosh. Yet we cling to it. Ideas of what human evolution ought to have been like still colour our debates.

Palaeoanthropologist Dean Falk debunks some modern myths in her brilliant book, The Fossil Chronicles, by comparing the case histories of two famous fossils. A career spent teasing meaning from the brain casts of fossil hominins (creatures more closely related to Homo sapiens than to chimpanzees) has led Falk into the debate on the cognitive abilities of Homo floresiensis. This dwarfed hominin - nicknamed the Hobbit - lived on the Indonesian island of Flores between approximately 95,000 and 14,000 years ago, and was discovered in 2003 (see Nature 431, 1055-1061; 2004). Falk also describes Raymond Dart's 1924 discovery in South Africa of a juvenile skull of Australopithecus africanus, the Man-Ape of South Africa, and locates an unpublished manuscript by Dart on the find that chimes

"Brains might be small, but they can still pack a punch." with her views.

Almost every time someone claims to have found a new species of hominin, someone else refutes

it. The species is said to be either a member of Homo sapiens, but pathological, or an ape. Brickbats of the first kind were levelled recently at $H$. floresiensis - that it wasn't a genuine species, but a modern human suffering from one of several kinds of microcephaly or from cretinism. But they had also been aimed at Neanderthal Man, discovered back in 1856, and thought by some to be the remains of a Mongolian Cossack from the Napoleonic wars. Accusations of apishness were aimed at $A$. africanus, described by Dart in these pages in 1925; and at Sahelanthropus tchadensis, nicknamed Toumaï, a very primitive putative hominin from Chad, discovered in 2001.

Dart's original paper on A. africanus was, it is true, long on waffle and short on substance. But the reason that this small-brained, possibly erect-walking creature took two decades to be accepted as a hominin was
D NATURE.COM For more on Homo floresiensis skull scans:

go.nature.com/xzblgge

that researchers were in thrall to the idea that the expansion of the human brain came first, before the adoption of a fully erect gait. This preconception was supported by the discovery of the large-brained, apejawed Piltdown Man in 1912. The fact that it took 40 years to expose Piltdown as a fraud is a mark of how deeply rooted such prejudices can be.

Falk describes her work refuting the idea that the small brain of the Hobbit implies the creature might have had a congenital disorder of brain growth. She shows that its brain most resembled that of Homo erectus, another antique hominin, and was developed in areas associated with cognitive abilities that would have supported making the simple tools with which its fossils are associated. Yet the Hobbit has a closer resemblance in its general anatomy to Australopithecus, suggesting - again contrary to preconception - that hominins emerged from Africa much earlier than thought.

The best parts of the book are those in which Falk traces the history of Dart. The Australian anatomist was exiled to South Africa by his mentor at University College London, Grafton Elliot Smith. In Africa, chance threw in his way the brain cast and skull of a juvenile hominin: a creature he named A. africanus. After publishing his Nature paper, Dart was critically mauled by the London establishment - notably the 'Piltdown

Scans enabled researchers to model the brain shape of Homo floresiensis.
Committee' who believed in the fake fossil and he almost deserted palaeoanthropology, devoting his energies to building up capacity at the then-fledgling University of the Witwatersrand in Johannesburg.

Almost, but not quite. Falk's investigation of Dart's papers at Witwatersrand has brought to light a monograph on A. africanus that Dart never published. In 1929 he sent it to Elliot Smith to submit to the Royal Society in London, but it was rejected, presumably on the basis of reports by the Piltdown Committee. Falk reveals that Dart had come to similar conclusions about the cognitive capacity of $A$. africanus as she has with $H$. floresiensis, providing circumstantial evidence for her link between Australopithecus and the Hobbit, and for an earlier African diaspora. Brains might be small, but they can still pack a punch.

Falk's book is worth reading just for the unearthing of this otherwise lost manuscript, vital to the history of palaeoanthropology. That it sparkles with scholarship and wit is icing on the cake.

Henry Gee is a Senior Editor of Nature. 